\title{
Development of Anti-e after Platelet Concentrate Transfusion
}

\author{
Sohaib Abu-Farsakh, Renee Bowen, Neil Blumberg and Majed A. Refaai ${ }^{\star}$ \\ Department of Pathology and Laboratory Medicine, University of Rochester Medicine, Rochester, NY, USA
}

*Corresponding author: Majed Refaai, MD, University of Rochester, 601 Elmwood Avenue, Box-608, Rochester, NY 14642, USA, Tel: 585 276-3927; E-mail: m.refaai@rochester.edu

Received date: Aug 07, 2015, Accepted date: Sep 09, 2015, Publication date: Sep 14, 2015

Copyright: (c) 2015 Abu-Farsakh S, et al. This is an open-access article distributed under the terms of the Creative Commons Attribution License, which permits unrestricted use, distribution, and reproduction in any medium, provided the original author and source are credited.

\begin{abstract}
Platelet concentrates (PC) is prepared from donated whole blood units by centrifugation and subsequent pooling of 4-6 units Advancing Transfusion and Cellular Therapies Worldwide Advancing Transfusion and Cellular Therapies Worldwide. Thus, PC may contain a small amount of donor RBC. We report a case of a 60 year-old male patient with past medical history of coronary artery disease, who presented to our emergency department with shortness of breath. Previous medical history indicated a recent admission, one month prior, to another local hospital for shock and respiratory failure. Type and screen (T/S) done at that time reveal an $\mathrm{O}+$ blood type with negative antibody screen. During that admission, the patient received only 5 doses of PC (2-group O+, 2-group O-, and 1-group A-). $\mathrm{He}$ denied any other recent blood product transfusions at any other facility. Our current $\mathrm{T} / \mathrm{S}$, and before any transfusions, showed a positive antibody screen. A panel for antibody identification was performed. The antibody reacted with 9 out of 10 reagent cells. The reactivity was predominately at room temperature and $37^{\circ} \mathrm{C}$ phases indicating an IgM class antibody. Some reactivity was also seen at AHG (anti-human globulin) phase indicating an IgG class antibody. The auto control was negative. Testing additional cells revealed an anti-e specificity. Patient's "e" antigen typing was performed and found to be negative indicating that this is a true allo-antibody. Since anti-e antibody predominantly exists as an IgG immunoglobulin class antibody, the presence of IgM class reactivity suggests that this may be a newly developed antibody. This case illustrates that antibodies to RBC antigens can develop after platelet transfusion.
\end{abstract}

\section{Keywords: Transfusion; Platelet concentrate; Transfusion Case Report}

complications; Anti-e antibody

\section{Introduction}

In transfusion medicine, two forms of platelet products are available for transfusion, apheresis platelets and pooled platelets, also known as platelet concentrates (PC). The former is collected from a single donor via an apheresis procedure, while the later is prepared by isolating platelets from donated whole blood units by centrifugation and subsequent pooling of 4 to 6 units [1]. By FDA and Advancing Transfusion and Cellular Therapies Worldwide Advancing Transfusion and Cellular Therapies Worldwide AABB regulations, a platelet transfusion dose of either form should contain at least $3-4 \times 10^{11}$ platelets. Both forms of platelet products contain a small amount of donor red blood cells (RBC). One study that retrospectively analyzed $1014 \mathrm{Rh}$ - patients who received $\mathrm{Rh}+$ platelets found that no patients who received only apheresis platelets developed anti-D while $3.8 \%$ of patients who received PC developed anti-D, which may suggest a lesser degree of RBC contamination in apheresis platelets [2].

RBC transfusion is frequently limited by the presence of antibodies to $\mathrm{RBC}$ antigens in the recipient's serum, which can be either naturally occurring or acquired. Antibodies to missing $\mathrm{ABO}$ antigens are naturally occurring and generally appear in the serum by four to six months of age. Antibodies to the other RBC antigens usually develop as an immunologic response in the recipient following exposure to allogenic antigens by means of blood transfusion or pregnancy. The Rh system antigens belong to the latter category and the most clinically important antigens in that system are D, C, c, E, and e [3].
We report a case of a 60 year old white male patient with past medical history of hypertension, diabetes, coronary artery disease, congestive heart failure, COPD, and alcoholic cirrhosis, who presented to our emergency department with shortness of breath. Previous medical history indicated a recent admission, one month prior, to another local medical center for shock, pulmonary embolism, and respiratory failure. Type and screen done at that time at the other hospital revealed an $\mathrm{O}$ positive blood type with negative antibody screen performed using solid phase testing method. During that admission, the patient received 5 doses of $\mathrm{PC}$ (two group $\mathrm{O}$ positive, two group $\mathrm{O}$ negative, and one group A negative) with no $\mathrm{RBC}$ or fresh frozen plasma (FFP) transfusion. The patient denied any other recent blood product transfusions at any other facility. He also denied any previous surgeries, major trauma, or any previous emergency room admissions.

The current type and screen done at our blood bank during this admission and before any transfusions showed a positive antibody screen. A panel for antibody identification was performed. The antibody reacted with 9 out of 10 reagent cells. The reactivity was predominately at room temperature and $37^{\circ} \mathrm{C}$ phases indicating an IgM class antibody. Some reactivity was also seen at AHG (anti-human globulin) phase indicating an IgG class antibody. The auto control was negative.

After additional cells were tested, the antibody specificity was identified as anti-e. Three reagent cells that are positive for the " $\mathrm{e}$ " antigen reacted positively and 3 reagent cells negative for the "e" antigen did not react. For confirmation, the patient's " $e$ " antigen typing was performed and it was found to be negative indicating that this is a 
true allo-antibody. Phenotyping of the patient's RBCs for other $\mathrm{Rh}$ antigens was positive for " $c$ " and " $E$ " and negative for "C" as well as "e". No blood product transfusion was given to the patient at our hospital by the time of this workup. Since anti-e antibody predominantly exists as an IgG immunoglobulin class antibody, the presence of IgM class reactivity suggests that this may be a newly developed antibody.

\section{Discussion}

This case illustrates that antibodies to $\mathrm{RBC}$ antigens can develop after platelet transfusion. Platelets express $\mathrm{ABO}$ and HLA class 1 antigens on their membrane surface but do not express Rh antigens, however, PC also contain a small amount of donor RBCs that carry $\mathrm{Rh}$ antigens. Previous studies have shown a low rate of development of anti-D after D-positive platelets transfusion to D-negative recipients $[2,4]$, and case reports have documented sporadic cases of development of other $\mathrm{Rh}$ antibodies after transfusion with apheresis platelets [5] or platelets concentrates [6].

The role of bacterial components in the production of naturally occurring antibodies directed against $\mathrm{ABO}$ red cell antigens is well known. Some studies have also described a possible association between bacterial infections and the development of antibodies to non-ABO red cell antigens, such as Kell or Kidd blood group antigens [7-11]. In addition, there are reports of spontaneously generated antibodies that occurred without exposure to allogenic antigens, such as anti-E and other antigens of the Rh system, anti-Lua, anti-Dia, anti$\mathrm{Xga}$, and antibodies to low-incidence antigens as well as anti-HLA antibodies [12]. In our case, no sepsis or serious infections were reported between both admissions. The use of $\mathrm{ABO}$ non-identical platelet transfusions is associated with higher alloimmunization rates [13]. It is possible that this group O patient's receipt of group A platelet concentrates facilitated his alloimmunization to the " $\mathrm{e}$ " antigen.

\section{References}

1. Yaun S, Goldfinger D (2015) Clinical and laboratory aspects of platelet transfusion therapy. In: Bassow DS (ed) UpToDate, Waltham, MA.
2. Cid J, Carbassé G, Pereira A, Sanz C, Mazzara R, et al. (2011) Platelet transfusions from D+ donors to D- patients: a 10-year follow-up study of 1014 patients. Transfusion 51: 1163-1169.

3. Kleinman S (2015) A primer of red blood cell antigens and antibodies. In: UpToDate, Bassow, DS (edtn), UpToDate, Waltham, MA.

4. Cid J, Lozano M, Ziman A, West KA, O'Brien KL, et al. (2015), Low frequency of anti-D alloimmunization following $\mathrm{D}+$ platelet transfusion: the Anti-D Alloimmunization after D-incompatible Platelet Transfusions (ADAPT) study. Br J Haematol 168: 598-603.

5. Kitazawa J, Nollet K, Morioka H, Tanaka K, Inomata M, et al. (2011) Non-D Rh antibodies appearing after apheresis platelet transfusion: stimulation by red cells or microparticles? Vox Sang 100: 395-400.

6. Yun JW, Kang ES, Ki CS, Koh KC, Kim DW (2012) Sensitization to multiple $\mathrm{rh}$ antigens by transfusion of random donor platelet concentrates in a -D-phenotype patient. Ann Lab Med 32: 429-432.

7. Kim HH, Park TS, Lee W, Lee SD, Kim HO (2005) Naturally occurring anti-Jk(a). Transfusion 45: 1043-1044.

8. Savalonis JM, Kalish RI, Cummings EA, Ryan RW, Aloisi R (1988) Kell blood group activity of gram-negative bacteria. Transfusion 28: 229-232.

9. Kanel GC, Davis I, Bowman JE (1978) "Naturally-occurring" anti-K1: possible association with mycobacterium infection. Transfusion 18: $472-473$.

10. Judd WJ, Walter WJ, Steiner EA (1981) Clinical and laboratory findings on two patients with naturally occurring anti-Kell agglutinins. Transfusion 21: 184-188.

11. McGinnis MH, Leiberman R, Holland PV (1979) The Jkb red cell antigen and gram-negative organisms. Transfusion. 19: 663.

12. Klein HG, Anstee DJ (2005) Mollison's Blood transfusion in clinical practice. (11thedn) Oxford: Wiley-Blackwell: 67-72.

13. Henrichs KF, Howk N, Masel DS, Thayer M, Refaai MA, et al. (2012) Providing ABO-identical platelets and cryoprecipitate to (almost) all patients: approach, logistics, and associated decreases in transfusion reaction and red blood cell alloimmunization incidence. Transfusion. 52: 635-640. 